\title{
Surface texture modification for improved roping behaviour of aluminium alloy 6016
}

\author{
T.A. Bennett ${ }^{1,2, a}$, R. H.Petrov ${ }^{3, b}$ and L.A.I. Kestens ${ }^{2,3, c}$ \\ ${ }^{1}$ Materials Innovation Institute (M2i), Mekelweg 2, 2628 CD, Delft, The Netherlands \\ ${ }^{2}$ Department of Materials Science and Engineering, Delft University of Technology, Mekelweg 2, \\ 2628 CD, Delft, The Netherlands \\ ${ }^{3}$ Department of Materials Science and Engineering, Ghent University, Technologiepark 903, \\ B-9052 Ghent, Belgium
}

âT.A.Bennett@tudelft.nl, ${ }^{\text {b Roumen.Petrov@UGent.be, }{ }^{c} l e o . k e s t e n s @ u g e n t . b e ~}$

\begin{abstract}
Keywords: Aluminium; Roping; Electron backscatter diffraction; Particles; Texture banding
\end{abstract}
\begin{abstract}
The effect of two different intermediate annealing (IA) treatments on texture banding in a roping prone aluminium alloy was investigated. It was found that texture banding occurred in the final annealed material that underwent an IA treatment consisting of slow heating in which there was significant interaction between the recrystallizing grains and the particles in the material. A more uniform distribution of orientations in the final annealed material was obtained in the case of an IA treatment with fast heating so that there was no significant effect of particles on recrystallization.
\end{abstract}

\section{Introduction}

It is well established that the $6 \mathrm{XXX}$ series aluminium alloys, which are used in automotive applications are prone to roping [1-4]. Various publications have shown that there is a correlation between the occurrence of roping and the spatial distribution of specific crystallographic orientations [1-4]. In addition, it appears that the roping tendency of a material is connected with the precipitation state [5]. This is possible since the precipitation state can influence the recrystallization texture of the material. For example, Engler and Hirsch [6] investigated the recrystallization texture and plastic anisotropy in Al-Mg-Si sheet alloys [6], and reported different intensities of the $\{100\}<001>$ Cube component in the final recrystallised textures in materials which had different dispersoid (particles dispersed in the material) densities. The Cube intensity was higher in the material that had a significant density of dispersoids compared to the case with a considerably lower fraction (of dispersoids) [6]. It was assumed that particle stimulated nucleation (PSN) was retarded by the dispersoids but Cube grains were still able to successfully nucleate at Cube bands [6]. Since particles can affect the final recrystallization texture formed in a material, it is conceivable that they can have some effect on the spatial distribution of crystallographic grains in these materials. As such, this paper explores the connection between particles and the eventual spatial distribution of Cube grains in a $6016 \mathrm{Al}$ alloy.

\section{Experimental methods}

The 6016 alloy investigated had a nominal composition of Al-1.0Si-0.45Mg-0.25Fe-0.1Mn (all in wt.\%). The starting material was an industrially produced hot band (4 $\mathrm{mm}$ thickness), laboratory cold rolled to a gauge of $2.6 \mathrm{~mm}$ (hereafter CR_A). The CR_A material was laboratory heat-treated in two Intermediate Annealing (IA) cycles (Fig. 1). In the IA_1 treatment, the material was heated in a box furnace to temperatures in the range of $350{ }^{\circ} \mathrm{C}-400{ }^{\circ} \mathrm{C}$ at a rate of $30{ }^{\circ} \mathrm{C} / \mathrm{hr}$ (Fig. 1), held at annealing temperature for 1 hour, and then slowly cooled to room temperature. In the IA2 treatment, the CR_A material was immersed in a salt bath pre-heated to $410{ }^{\circ} \mathrm{C}-450{ }^{\circ} \mathrm{C}$, held at annealing temperature for 1 minute, and then water quenched (Fig. 1). 


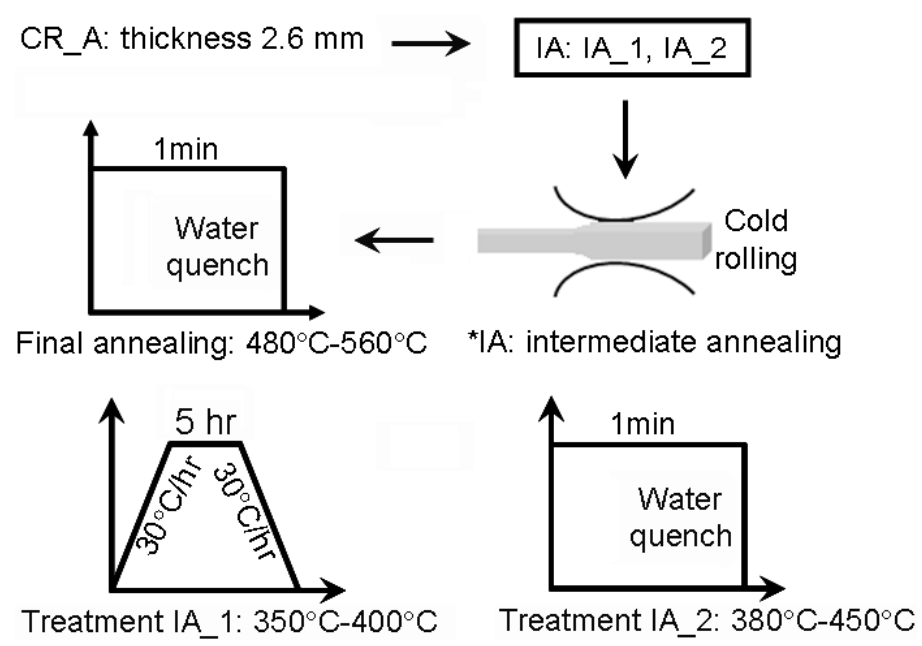

Fig. 1: Schematic illustrating the thermo-mechanical treatments that were compared.

The IA1 treatment was expected to result in significant interaction between the recrystallizing grains and the particles present in the initial material. In contrast, it was expected that such an interaction would be significantly lower in the IA2 treatment. Both IA-treated materials were laboratory cold rolled to a final thickness of $\sim 1 \mathrm{~mm}$ followed by annealing at temperatures in the range $480{ }^{\circ} \mathrm{C}-560{ }^{\circ} \mathrm{C}$ for 1 minute.

The Image $\mathrm{J}$ (version 1.38x) software was used to analyse scanning electron micrographs of the CR_A material in order to determine the particle density. The microtexture of all samples was characterized using electron backscatter diffraction (EBSD). Samples for EBSD characterization were prepared by conventional mechanical grinding before electrolytically polishing using an electrolyte of $7.8 \%$ perchloric acid, $9 \%$ water, $73.1 \%$ ethanol and $10 \%$ butylcellulose (cooled to temperatures in the range $5{ }^{\circ} \mathrm{C}$ to $-10{ }^{\circ} \mathrm{C}$ ) with a voltage of $25 \mathrm{~V}$ and a flow rate of 18 for $60 \mathrm{~s}$. EBSD measurements were performed on a FEI XL30 scanning electron microscope (accelerating voltage: $20-25 \mathrm{kV}$, tilt angle: $75^{\circ}$, working distance: $25 \mathrm{~mm}$ ). Step sizes of $1 \mu \mathrm{m}$ and $8 \mu \mathrm{m}$ were used for as cold-rolled and fully recrystallized materials, respectively and the orientation contrast data were analysed using the TSL OIM Analysis software (version 4.6). A total area of $1 \mathrm{~mm} \times 10$ $\mathrm{mm}(\mathrm{RD} \times \mathrm{TD})$, on average, was examined from each of the fully recrystallized materials. The textures were compared by plotting the orientation distribution functions (ODFs). These were calculated by the harmonic series expansion method on the assumption of orthorhombic sample symmetry $\left(l_{\max }=22\right.$, Gaussian spread $\left.=5^{\circ}\right)$. In this paper, only the $\varphi_{2}=0^{\circ}, \varphi_{2}=45^{\circ}$ and $\varphi_{2}=65^{\circ}$ sections are shown since they contain the important texture components in this alloy. Hence forth, the materials will be designated as follows: intermediate annealed at temperatures in the range, $350{ }^{\circ} \mathrm{C}-400^{\circ} \mathrm{C}$ and $380{ }^{\circ} \mathrm{C}-450{ }^{\circ} \mathrm{C}$ as IA_1 and IA_2 respectively. The corresponding cold rolled and annealed materials will be referred to as A_1 and A_2.

\section{Results and discussion}

Grain orientation texture. Fig. 2 shows the distribution of particles in the CR_A (pre-IA) material. The material has a high $\left(1.4 * 10^{11} \mathrm{~m}^{-2}\right)$ density of particles. 


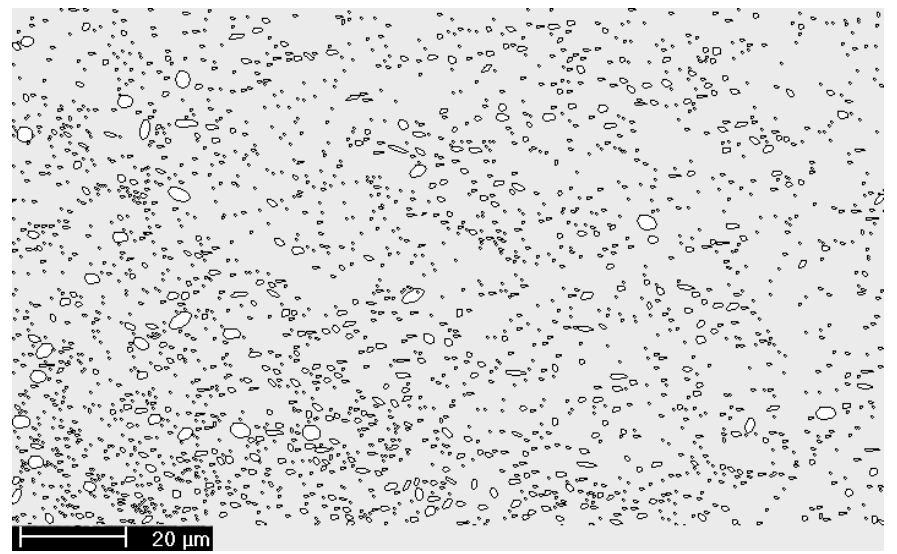

Fig. 2: SEM micrograph showing particles in the initial (pre-IA) material. The micrograph was thresholded using Image $J$ version $1.38 x$ in order to better visualize the particles.
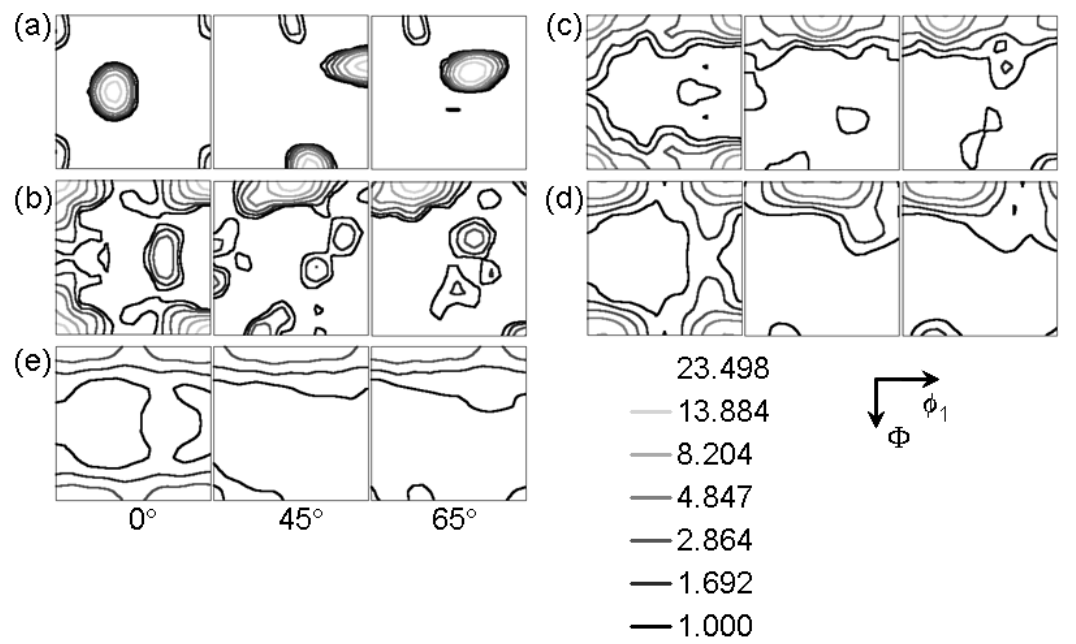

Fig. 3: (a)-(e) $\varphi_{2}=0^{\circ}, 45^{\circ}$ and $65^{\circ}$ sections of the orientation distribution function (ODF) for (a) CR_A (initial pre-IA), (b) IA_1, (c) IA_2, (d) A_1 and (e) A_2 materials. All are plotted on the same scale shown in the right of the figure.

Fig. 3 shows the through-process texture evolution. The CR_A material (Fig. 3(a)) is comprised of a $\beta$-fibre texture with the $\mathrm{S}$ component having the maximum intensity of $\sim 23.5$ times random compared to the $\mathrm{B}$ and $\mathrm{C}$ components with values of $\sim 17.5$ and 18.8. It is clear from Figs $3(\mathrm{~b})$ and (c) that the prolonged interaction between the particles with the recrystallizing grains has led to a stronger texture after the IA_1 treatment compared to the IA_2 case. A Cube texture (intensity $\sim 15.0$ times random), Fig. 3(b), formed as a result of the IA_1 treatment. The P component is also observed in Fig. 3(b) although with an intensity of only $~ 3.3$ times random. The Cube intensity resulting from the IA_1 treatment is stronger than its counterpart that occurs after IA_2. In that case, the Cube intensity is $\sim 9.6$ times random (Fig. 3(c)). The final annealing textures (Fig. 3(d) and (e)) are weaker than those of the IA in both cases. The Cube intensity of the A_1 material is $\sim 5$ times random. The highest intensity of $\sim 3.0$ times random spreads from the direct Cube to the $\left\{\begin{array}{lllll}0 & 0 & 1\end{array}\right\}\left\langle\begin{array}{lll}2 & 1 & 0\end{array}\right)$ $\mathrm{CH}$ component in the A_2 material (Fig. 3(e)).

Grain size, morphology and spatial distribution. The spatial distribution of specific orientations is examined since it is well established [1-4] that this parameter is crucial to the roping behaviour of a material. Fig. 4 shows grains that are within $15^{\circ}$ of the exact, direct $\{100\}<001>$ Cube orientation. 


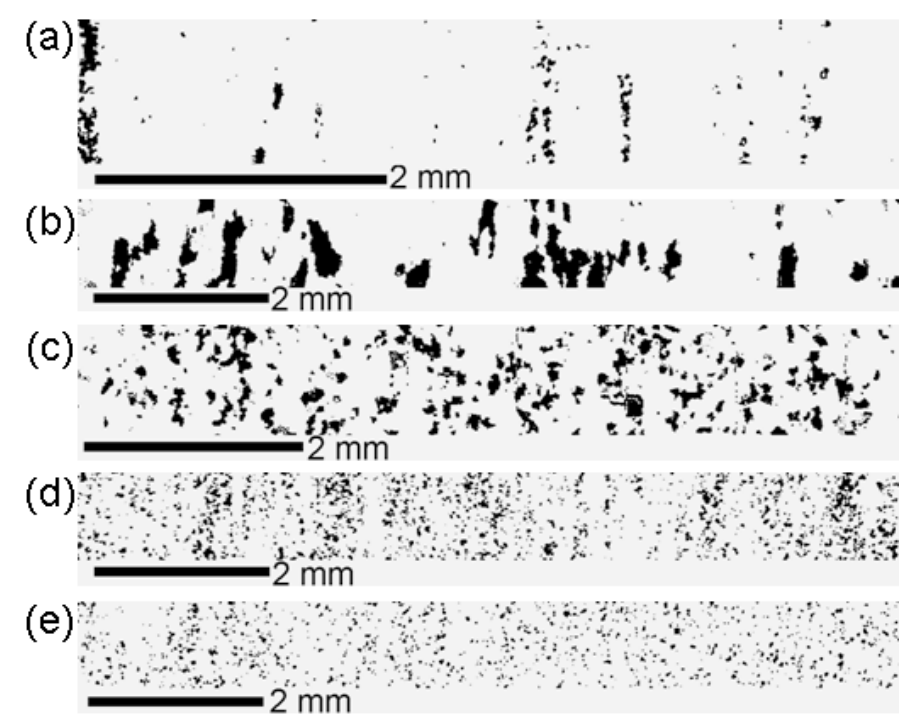

Fig. 4: EBSD maps shaded so that only grains that are within $15^{\circ}$ of the exact $\{001\}<100>$ Cube component are shown in the (a) CR_A, (b) IA_1, (c) IA_2, (d) A_1 and A_2 materials.

Cube grains are emphasized since it was shown previously that of all orientations considered, they display the highest banding character [8]. It is clear from Figs 4(a) and (b) that the number of Cube grains in the CR_A and IA_1 materials is not very high. The IA_1 treatment resulted in coarse, elongated grains. Grains in the IA_2 material (Fig. 4(c)) are smaller and more equiaxed compared to those in the IA_1 case. The grains in the IA_1 material are on average twice as large as those from the IA_ 2 treatment. As determined from line intercepts, the average size of the grains in the IA_1 and IA_ 2 material is $\sim 89 \mu \mathrm{m}$ and $\sim 43 \mu \mathrm{m}$, respectively.

The grain size of both materials was refined (Figs 4(d) and (e)) by the cold rolling and subsequent annealing (at $480{ }^{\circ} \mathrm{C}-560{ }^{\circ} \mathrm{C}$ for 1 minute). The average grain size of the A_1 and A_2 materials (Figs 4(d)-(e)) is $\sim 25 \mu \mathrm{m}$ and $\sim 21 \mu \mathrm{m}$, respectively. While the average grain sizes of the A_1 and A_ 2 materials are similar, it is clear that their spatial distributions differ. The Cube grains in the A_1 material are banded but more uniformly distributed in the A_2 case (Fig. 4(e)). Comparing Figs 4(b) with (e) and 4(c) with (e) reveals that a high (>50\%) area fraction of Cube grains in the IA stage is not a requirement for these grains to be banded in the final recrystallized material. The A_1 and A_2 materials had the same initial state, the CR_A material (Figs 3(a) and 4(a)). Therefore, the different recrystallization mechanisms that occur during the IA_1 and IA_2 treatment lead to a difference in the spatial distributions of Cube grains in the A_1 and A_2 materials (Figs 4(d)-(e)).

Recrystallization mechanisms during IA. During the IA_1 treatment the material was slowly heated to temperatures in the range of $350{ }^{\circ} \mathrm{C}-400^{\circ} \mathrm{C}$. This slow heating leads to different recrystallization mechanisms compared to the IA_2 treatment. The slow heating rate of the IA_1 treatment means that the material recovered, which reduced the driving force for recrystallization. The particles in the CR_A material (Fig. 2) should also significantly interact with the recrystallizing grains during the prolonged heating. As is well established, depending on the size of the particles with which the recrystallizing grains interact, the number of potential nuclei may be increased by PSN or recrystallization may be inhibited by Zener drag [9].

In order to estimate the possible contributions from PSN and Zener drag, the particles in the CR_A material (Fig. 2) were separated according to their size. The fraction of potential PSN sites was determined using the criterion that they must be at least $1 \mu \mathrm{m}$ large to initiate PSN [10] (with the understanding that since SEM micrographs were being evaluated particles smaller than $100 \mathrm{~nm}$ would be missed and the influence of Zener drag may be underestimated). $\sim 20 \%$ of all particles satisfy the above criterion. These particles have an average area of $1.6 \mu \mathrm{m}^{2}$. Therefore, the weak P component observed in Fig. 3(b) appears to have resulted from PSN during the annealing. The 
remaining fraction, $\sim 80 \%$, of particles, with average area of $0.3 \mu \mathrm{m}^{2}$, is sufficiently small to cause Zener drag. Zener drag appears to also be more effective than PSN during the IA_1 treatment, although the Cube intensity (15 times random) is relatively modest. The coarse grains observed in Fig. 4(b) means that only a small fraction of recrystallization nuclei were able to grow during the IA_1 treatment.

The net driving force for recrystallization in the presence of particles, may be expressed as [9],

$$
\mathrm{P}=\mathrm{P}_{\mathrm{D}}-\mathrm{P}_{\mathrm{C}}-\mathrm{P}_{\mathrm{Z}}=\frac{\alpha \rho \mathrm{Gb}^{2}}{2}-\frac{2 \gamma_{\mathrm{b}}}{\mathrm{R}}-\frac{3 \mathrm{~F}_{\mathrm{v}} \gamma_{\mathrm{b}}}{\mathrm{d}_{\mathrm{P}}}
$$

where, $\mathrm{P}_{\mathrm{D}}$ and $\mathrm{P}_{\mathrm{C}}$ are contributions from the stored energy of deformation $\left(\mathrm{P}_{\mathrm{D}}\right)$ and the retarding pressure $\left(\mathrm{P}_{\mathrm{C}}\right)$ due to the grain boundary curvature, respectively [9]. The Zener drag, $\mathrm{P}_{\mathrm{Z}}$, increases with increasing volume fraction $\left(F_{v}\right)$ of particles for a given particle size $\left(d_{P}\right)$. Figs 2 and $4(b)$ show that the microstructure resulting from the IA_1 treatment would have resulted from a compromise between Zener drag and PSN. It appears that Zener drag was successful in restricting grain boundary motion of many boundaries and thereby resulted in only a low fraction of viable recrystallization nuclei during the IA_1 treatment.

Zener drag vs. PSN. Engler [11] found that a sharp Cube texture formed after recrystallization of a specimen with a bimodal particle size distribution consisting of small dispersoids and large constituent particles. He explained that the dispersoids inhibited the growth of PSN grains since the strong Zener drag (exerted by the dispersoids) led to an increase in the critical size $\left(d_{\text {crit }}\right)$ nuclei must possess in order to grow [11]. Further, the grains nucleated at large particles will grow only if $d_{\text {crit }}$ is smaller than the deformation zone $(\lambda)$ surrounding the particle. Therefore, if the Zener drag is strong enough so that $d_{\text {crit }}$ exceeds $\lambda$ then grains nucleated by PSN cannot grow [11]. It was assumed that the strong Cube texture resulted since Cube grains that nucleate at Cube-bands could become larger than $d_{\text {crit }}$ through subgrain growth or coalescence, and therefore grow and dominate the microstructure. While the Cube intensity was the highest in the ODF (Fig. 3(b)), since the P component also developed, it appears that the Zener drag exerted by the small particles was not strong enough to completely suppress the growth of PSN grains. That is, while the overall number of successful nuclei was significantly lower in the IA_1 treated material than in the case of the IA_2 treatment (compare Figs 4(b) and (c)), there was apparently a sufficient number of PSN-grains with sizes that exceed $d_{\text {crit }}$ so that a more extensive development of the Cube texture was prevented (during the IA_1 treatment).

An important observation from Fig. 4(b) is that a significant fraction of Cube grains in the IA material is not necessary for banding to occur in the final annealed materials (Fig. 4(d)). In fact, the number of Cube grains in the IA_2 material is higher than in the IA_1 case but the corresponding area fraction $(16.8 \%)$ in the latter is not that different from that of the former $(15.9 \%)$. Based on this observation, it appears that the IA texture strength has a secondary influence on (texture) banding and ultimately the roping behaviour, compared to the grain size and morphology of the materials. This is not surprising since Wittridge and Knutsen [12] reported a higher level of roping in a 3002 aluminium alloy with coarse, elongated grains compared to the material with smaller, more equiaxed grains.

\section{Summary}

The effect of two different IA treatments on the texture banding in a 6016 aluminium alloy was investigated. It was found that texture banding of $\{100\}<001>$ Cube grains is promoted by a significant interaction between recrystallizing grains and particles during IA. A relatively uniform distribution of the grains is obtained in absence of this interaction. It appears that the IA texture strength has a secondary influence on texture banding and ultimately the roping behaviour, compared to the grain size and morphology of the materials. 


\section{Acknowledgements}

This research was carried out under the project number MC4.05238 in the framework of the Research Program of the Materials Innovation Institute M2i (www.m2i.nl), the former Netherlands Institute for Metals Research. Discussions with Ir. Stijn Kusters, Prof. Marc Seefeldt and Prof. Paul Van Houtte of Katholieke Universiteit Leuven and Dr. Lin Zhuang, Dr. Petar Ratchev and Mr. Peter de Smet of Corus and Aleris are greatly appreciated. Mr. Marnix van Dorpe is gratefully acknowledged for help with the laboratory rolling experiments.

\section{References}

[1] O. Engler and E. Brünger: Mater. Sci. Forum Vol. 396-402 (2002), p. 345.

[2] G.J. Baczynski, R. Guzzo, M.D. Ball and D.J. Lloyd: Acta Mater. Vol. 48 (2000), p. 3361.

[3] H. Jin and D.J. Lloyd: Mater. Sci. Eng. Vol. A403 (2005), p. 112.

[4] P.D. Wu, D.J. Lloyd, A. Bosland, H. Jin and S.R. MacEwen: Acta Mater. Vol. 51 (2003), p. 1945.

[5] O. Engler and J. Hirsch: Mater. Sci. Eng. Vol. A336 (2002), p. 249

[6] O. Engler and J. Hirsch: Mater. Sci. Eng. Vol. 217-222 (1996), p. 479.

[7] P. Van Houtte: MTM-FHM Software Version, second edition Leuven, M-KU (1995).

[8] T.A. Bennett, R.H. Petrov and L.A.I. Kestens: Scripta Mater. Vol. 61 (2009), p. 733.

[9] F.J. Humphreys and M. Hatherly: Recrystallization \& Related Annealing Phenomena, $2^{\text {nd }}$ edition, 2004, p. 307.

[10] F.J. Humphreys: Acta Metall. Vol. 25 (1977), p. 1323.

[11] O. Engler: Mater. Sci. Forum Vol. 273-275 (1998), p. 483.

[12] N.J. Wittridge and R.D. Knutsen: Mater. Sci. Eng. Vol. A269 (1999), p. 205. 